\title{
TNCs as embedded social communities: transdisciplinary perspectives
}

\author{
James R. Faulconbridge \\ Geography, Lancaster Environment Centre, Lancaster University, Lancaster, UK
}

\begin{abstract}
Published as Faulconbridge JR (2010) TNCs as embedded social communities: transdisciplinary perspectives. Critical Perspectives on International Business 6 (4) 273-290
\end{abstract}

\begin{abstract}
Purpose: In this paper I explore the value of transdisciplinary dialogues for advancing critical perspectives on international business. Specifically, I consider how conceptualisations of transnational corporations as embedded social communities can be advanced through dialogues and collaborations between two broadly defined scholarly communities, economic geographers and organizational sociologists.
\end{abstract}

Approach: The paper is conceptual and reviews existing work by economic geographers and organizational sociologists useful for studying transnational corporations. Specifically the paper considers how economic geographers' work on the affects of institutions on firms can be brought together with organizational sociologists' work on identity regulation to generate new lines of enquiry about the role of transnational identity regulation in firms.

Findings: It is shown that pragmatic rather than adversarial dialogues can overcome the limitations of disciplinary approaches and develop new questions about, and more sophisticated studies of, international business and transnational corporations, as long as the inherent dangers of transdisciplinary working are recognised and avoided. 
Originality: The paper takes a different approach to existing discussions of the value of transdisciplinary collaboration for studying international business, explicitly advocating a pragmatic approach that involves collaboration between researchers from related paradigms so as to generate new questions for research rather than an approach that involves critique and counter-critique of work from starkly contrasting research paradigms.

Keywords: transnational corporation; embeddedness; institutions; identity regulation; transdisciplinary

Paper type: Viewpoint

\section{Introduction}

The main aim of this paper is to explore the value of transdisciplinary dialogues for allowing the advancement of critical perspectives on international business and work on transnational corporations (TNCS) in particular. Specifically, the paper considers how dialogues between two subsets of the broad groups that I label economic geographers and organizational sociologists can advance understanding of TNCs as embedded social communities.

There have been a number of attempts to debate the importance and value of dialogue between scholars from the disciplines of geography and management studies (see for example Clark and Wrigley, 1997; Coe and Wrigley, 2006; Palmer et al., 2006). At times this debate has been fractious, leading to accusations of overly critical reviews of one-another's work and claims that oversimplifications have led to the 'balkanizing' of one-another's research field. There have also been more general debates about the nature and merits of transdisciplinary research. Here I use the term transdisciplinary to refer to a type of research that is distinct from multidisciplinary and interdisciplinary approaches. Specifically I 
follow, amongst others, Weigngart and Stehr (2000) and Wickson et al. (2006) and define:

multidisciplinary approaches as research that involves teams from several disciplines who address the same problem from their own perspectives through their own questions; interdisciplinary approaches as research that involves teams from multiple disciplines addressing a problem through a focus on questions that overlap disciplines and create common interests; and transdisciplinary approaches as involving new questions which are inspired by existing research but that no discipline has previously asked or sought to answer and which do not exclusively fit with the theoretical concerns of one discipline. In this sense, the question of how to understand TNCs as embedded social communities is a transdisciplinary question that seeks to not simply conduct research in the overlapping spaces between the disciplines of economic geography and organizational sociology but to generate new questions for research, methods and priorities through a coming together of representatives of both disciplines.

There are, however, inherent challenges that transdisciplinary research faces. Most fundamentally theoretical allegiances and incompatibilities need to be put to one side to allow new questions to emerge and evolve. But at the same time the dangers of analytical dilution must be avoided and analytical magnification through research ensured. Similarly, constructive critique rather than stagnant consensus is vital and should not be lost in the name of transdisciplinary collaboration. However, without wanting to suggest these debates are unimportant, in this paper I want to circumvent more philosophical discussions about the merits of transdisciplinary research (but see Weingart and Stehr [2000] on such issues) in order to take the first steps towards outlining how a pragmatic approach to transdisciplinary research might allow geographers and management scholars to generate new questions and insights about the way TNCs operate as embedded social communities. 
In referring to TNCs as embedded social communities I seek to draw attention to two distinguishing features of management practice in cross-border organisations that have long troubled academics and practitioners alike. Embedded refers, following Polanyi (1944), to the way management and decision making in TNCs are influenced by geographically variable structures that shape cognitive, cultural, social and political logics. In particular, embedded refers to the way TNCs are always influenced by the structures of their home and host countries. Social communities alludes to the fact that management in TNCs is a political exercise involving multiple social actors that through their interactions, conflicts, negotiations and compromises determine the way a firm is governed and structured. I do not claim the idea of TNCs as either embedded or as social communities is new - see for example the expression of elements of the concept in the work of, amongst others, Dicken (2000), Dicken et al. (2001), Ferner et al. (2005, 2006), Gertler (2004), Hess (2004), Jones (2005; 2007), Morgan (2001a; 2001b) and Yeung (2005a, 2005b). Instead, this paper's originality is the consideration offered of the value of such a framing for generating new research question about not embeddedness, not the micro politics of management, not firm structure but about the dialectic causes and nature of management and social conflict in 'embedded social communities'. This is a subtle but important switch in emphasis that raises a series of interesting and important questions that are likely to be missed when solely focussing on embeddedness or the micro politics of management.

Before proceeding any further it is important that I acknowledge my particular positionality in relation to this issue. As part of my research on transnational law firms I have conducted research and written papers as part of a now established collaboration with Daniel Muzio, a member originally of Lancaster University Management School and more recently Leeds University Business School (see for example the research reported in Faulconbridge and Muzio 2007, 2008, 2009). As such, and as a self badged 
economic geographer, I am already wedded to the idea that collaboration between geographers and management scholars brings benefits to critical studies of international business. Here I want to offer my perspective on why such collaborations are important and fruitful and identify the type of advances such collaborations might generate when used to develop transdisciplinary approaches.

The rest of the paper is structured around two further sections. In the next section of the paper I consider what a subset of scholars allied to the groupings that I broadly label as economic geography and organizational sociology bring to the study of TNCs. My main argument is that the two groups have different but compatible strengths that when combined are well positioned to develop a number of crucial new transdisciplinary questions about the activities of TNCs. The example used to support this argument relates to what I call questions of 'transnational identity regulation' and unites fertile studies

of the role of identity regulation as a management strategy with studies of embedded TNCs to generate new questions for study. The final section then reflects on the implications of the approach presented in the paper for future collaborations across the geography- management 'divide'.

\section{Synergism rather than scepticism: the value of pragmatic collaboration}

In an important intervention in this journal, Yeung (2005a) suggests that 'organizational space' - the study of how TNCs create and manipulate different types of social space to facilitate their operations - is one way that geographers can enhance management scholars' understandings of international business. For Yeung, such an approach acts as an alternative to quantitative studies of international business that view space as a 'container' and as a variable in equations that represent the locational decision making 
logics of firms. This argument, that international business needs to be studied from a more sociological point of view, which takes space and its social construction seriously, is an important one and is fundamental to geographers' understandings of TNCs (see also Beaverstock, 2004; Bunnell and Coe, 2001; Currah and Wrigley, 2004; Faulconbridge, 2008a; Jones, 2005, 2007; Yeung, 2005b). However, here I want to take a different approach to arguing for the importance of bringing geographers' perspectives into dialogue with management perspectives on international business. My approach seeks less to identify the shortcomings of existing research by management or geography scholars and more to identify complementarities that exist in the work of the two groups. After all, as Burell and Morgan (1979) long ago argued, there is often more progress to be made through dialogue with those who share the same research paradigm and philosophy than there is through dialogue and critique across paradigms and philosophies. By developing a dialogue between the work of economic geographers and what I broadly label 'organizational sociologists' my aim is to talk within two related paradigms.

\subsection{Economic geography: identifying the constitution of relational space in TNCs}

Economic geography as a sub-discipline of geography covers a broad array of 'economic geographical' perspectives (Peck and Yeung, 2003). Much of the work by economic geographers would not lend itself to the type of transdisciplinary collaboration I want to promote here. For example, work on national and regional innovation systems (see Audretsch and Feldman, 1996; Edquist, 1997; Lundvall and Johnson, 1994) that focuses almost exclusively on the role of institutional actors in defining the nature of a business environment has much less to contribute to debates about TNCs as embedded social communities than the literature discussed below. It is, therefore, important to be clear about the claims I am making here about the research of economic geographers. I am suggesting that a subset of and not 
all economic geographical research, when coupled to a subset of and not all of organizational sociologists' research, might generate valuable transdisciplinary collaborations and questions. Indeed, in many ways the subsets of research I discuss below are already interdisciplinary. Therefore, my contribution is to consider ways of generating new lines of enquiry beyond the shared points of interest already identified.

In terms of economic geography, the body of work I am interested in here and which is most useful to studies of international business places economic sociology at the heart of analyses of the geographies of TNCs (on which see Peck, 2005). This already interdisciplinary work seeks to analyse the embedded nature of international economic activity and the way social actors within firms construct spaces of international business. Drawing on the work of Polanyi (1944) and Granovetter (1985), embeddedness has been used by economic geographers to capture the way all international business activities are grounded in societal structures that influence the cognitive, cultural, social and political characteristics of a firm's managers and workers and ultimately the firm's operations. In particular, the role of geographically variable institutions - defined as both formal rules and regulations and informal customs and norms following amongst others the work of Veblen (1919), Polanyi (1944), North (1990) and Hodgson (2006) - in shaping the structure and profitability of TNCs has been noted. In the economic geographical work I wish to draw on here this is referred to, following the intervention of Hess (2004), as 'societal embeddedness'. Specifically, the societal embeddedness of TNCs - i.e. the cognitive, cultural, social and political influences on business practices - is said to result from the place a TNC emerges from and the place a TNC operates in. The home-country leaves a distinguishing mark on the firm - thus for example making English firms and their management practices distinctive from French firms - but at the same time the unique features of host-country societies also influence and are influenced by 
management practice in each subsidiary. Dicken $(2000,276)$ describes this idea with the phrase 'places produce firms while firms produce places', the first part of the phrase alluding to the influence of homeand host-countries on TNCs' management practices and the second part the influence of TNCs on the host-country. As a result of this societal embeddedness, TNCs are said to be constantly adapting and hybridising their management practices to take account of the influence of home- and host-country institutions on operations (see for example Coe and Lee, 2006; Faulconbridge 2008b; Wrigley et al., 2005).

In addition, the subset of economic geographers who adopt an economic sociology inspired approach to studying TNCs have also pointed to the role of what Hess (2004) calls 'network embeddedness'. Similar to the ideas of Granovetter (1985), network embeddedness has been used to capture the way the existence and social constitution of relationships between spatially distributed individuals operating in TNCs (e.g. branch managers in London, Singapore and Hong Kong) influence international business activities. ${ }^{1}$ Specifically discussions of network embeddedness focus on:

"the network of actors a person or organization is involved in, i.e., the structure of relationships among a set of individuals and organizations regardless of their country of origin or local anchoring in particular places. It is most notably the 'architecture', durability and stability of these relations, both formal and informal, which determines the actors' individual network embeddedness (the relational aspect of network embeddedness) as well as the structure and

\footnotetext{
${ }^{1}$ Hess also identifies the role of territorial embeddedness, which departs significantly from the work of Polanyi (1944) and Granovetter (1985) and highlights the anchors that tie a firm to a particular place, such as reliance on a localised client base. Debates about territorial embeddedness have, however, less relevance to the analysis here and are, therefore, excluded from the main discussion.
} 
evolution of the network as a whole (the structural aspect of network embeddedness) ... Network embeddedness can be regarded as the product of a process of trust building between network agents, which is important for successful and stable relationships. Even within intrafirm networks, where the relationships are structured by ownership integration and control, trust between the different firm units and the different stakeholders involved might be a crucial factor" (Hess, 2004, 177).

The simultaneous influence of both the societal and network embeddedness identified by Hess (2004) has been shown by economic geographers to act as the basis for the production of relational space within TNCs. Management 'gets done' in this relational space as network embeddedness - spatial relationships between managers and workers - is used to manage the influences of societal embeddedness. This management involves negotiations about how, and the extent to which, home-and host-country societal influences shape the governance and structure of TNCs' subsidiaries. Hence, according to Yeung $(2005 b, 38)$, a relational approach to studying globalization recognises the role of "relational geometries which are neither actors (e.g. individuals and firms) nor structures (e.g. class, patriarchy and the state), but configurations of relations between and among them - connecting actors and structures through horizontal and vertical power relations". As such, a relational approach is supposed to be descriptive of management practice in TNCs, mapping the existence of relations between different social actors, but also analytical, revealing the social processes, politics and negotiations that characterise the type of spatial relationships involved in running a TNC. For Dicken et al. (2001), the relational space approach involves, therefore, three analytical steps. First the social actors and influences upon them need to be identified. Second, the socio-spatial relations between actors need to be characterised and studied. Third, the outcomes of these socio-spatial relations need to be charted 
and explained in the context of steps one and two. Step three also means unpacking the organizational structure and strategy that emerges from socio-spatial relations and the politics of these relations.

As such, geographers' unique contribution is to provide a way of analysing the complexities of the management of TNCs that takes account of the influence of diverse societal contexts on day-to-day management strategising and decision-making. By bringing together both an understanding of the nature of place-specific forms of societal embeddedness, and the way these influences get managed through network embeddedness, the messiness of the social life of TNCs comes into focus (Coe and Yeung, 2001). For example, Currah and Wrigley (2004) show how transnational retailers such as Tesco generate transnational communities of practice through which both home-country defined best practices get disseminated to overseas stores but also the adaptation of best practices to host-country contexts gets negotiated (e.g. when the home-country defined design of stores is seen as inappropriate in a particular country because of cultural norms relating to the role of supermarkets, the way they are used by shoppers and the services they provide). This negotiation involves compromises and inevitably clashes and corporate politics but also involves collaboration and learning as host-country norms relating to retail are learned from and sometimes implemented in the home-country of the firm.

Gertler (2004) similarly uses the tools of economic geography to show the role of home and host country institutions in shaping the nature of intra-firm relations - i.e. the way institutions influence the customs and norms that shape relationships between colleagues and between managers and workers as well as ways of working, what Gertler (2004) calls industrial practices. Specifically, Gertler (2004) shows through a comparison of manufacturers in Germany and the USA that, to use the language of work on national business systems (see Whitley, 1998), the different 'collaborative' and 'arm's length' 
institutional environments of the two countries produce workers and employers with different cultures relating to training. In Germany institutions lead to cultures that promote training and lifelong learning facilitated by the employing organisation because of the enforcement by institutions of long-term ties and collaboration between employers and employees. In contrast, in the USA the coordinating institutions do not promote such employer-employee relationships and result in employers having little desire to train workers and workers themselves having only short-term commitment to a firm and hence no desire to complete training. As a result, German firms attempting to setup manufacturing operations in the USA have faced a great deal of resistance when attempting to implement home-country ways of working in relation to training.

A case could be made, then, that economic geographers already have the tools to conceptualise the TNCs as embedded social communities, tools that can allow them to export ideas to other disciplines, such as management, as well as import them into economic geography (on which see Peck, 2005). Geographers are particularly well positioned to reveal how TNCs as social spaces of management are affected by societal embeddedness which in turn influences embedded network relations between managers and workers in the firm. Indeed, a number of geographers have, as part of a 'practice turn', used the insights generated by discussions of societal and network embeddedness as inspiration for the development of research that focuses on the day-to-day practices associated with managing the embedded international operations of firms (see for example Jones, 2005; Faulconbridge, 2008a, 2008b; Hall and Appleyard, 2009; Murphy, 2006). However, despite their 'practice turn', what these (the current author included) and other economic geographers are less adept at doing is revealing in detail the actions and micro politics that operate on a day-to-day basis in TNCs. Yeung (2005b) has made this critique before: whilst emphasising the politics of relational spaces, economic geographers have tended 
to be somewhat descriptive of the social tussles that define and are defined by these politics, identifying their occurrence but providing little in terms of micro-scale analysis of the way these tussles play-out on a day-to-day basis (see also Sunley, 2009). This is where the work of organizational sociologists comes in.

\subsection{Organizational sociologists: revealing the day-to-day micro politics of business spaces}

The body of research I refer to here as organizational sociology is broad in nature whilst all emerging from business/management schools. The aim here is to identify the most useful sub-set of this organizational sociological work for generating transdisciplinary dialogues. Specifically, I want to emphasise the way the common interest of a sub-set of economic geographers and a sub-set of organizational sociologists in 'sociology'-i.e. the social dynamics of management within organizations, the way social actors strategise and respond to management and, relatedly, the social, political and organizational outcomes of management practices - can be used to foster collaborative work designed to advance understanding of TNCs as embedded social communities. As such, and like the review above of economic geographers' work, I am not claiming that the work of organizational sociologists has to date ignored the benefits of interdisciplinary research; much of the existing work is highly interdisciplinary and draws on insights from sociology, politics, law etc.. Nor am I claiming that it is only the work I discuss below that can be used to frame transdisciplinary research about TNCs. Rather, I selectively draw on organizational sociologists' work to highlight how dialogue with the work of economic geographers creates opportunities for the emergence of new transdisciplinary questions about TNCs as embedded social communities. 
The subset of the organizational sociology literature that I want to draw on here includes, first, research labelled as 'critical management studies' which has developed over the past twenty years since the publication of the edited collection by Alvesson and Willmott (1992). More recently summarised in a reader edited by Grey and Willmott (2005) and a handbook edited by Alvesson et al. (2009), critical management studies has grown to be a diverse field that, as Adler et al. (2007) highlight, uses left leaning theory to question the social but also ecological justice of management practices as diverse as teamwork (see Ezzamel and Willmott, 1998) and environmental management (Beder, 2002), financialised management (Froud et al., 2006) and expectations of emotional labour in the workplace (Bolton and Boyd, 2003). Second, I also include work that addresses similar concerns but which may or may not sit squarely under the badge of critical management studies (see Ackroyd [2004] on what is and isn't critical management studies). This includes work on labour process theory that emphasises the role of conflict, resistance and misbehaviour in the workplace (Ackroyd and Thompson, 1999; Burawoy, 1979; Thompson, 2003) as well as power more generally (Clegg et al., 2006; Clegg and Palmer, 1996; Hardy, 1996). It also includes work on the firm as a community (of practice) (Adler et al., 2008; Orlikowski, 2002; Roberts, 2006; Swan and Scarborough, 2005), studies of the knowledge/professional worker (Ackroyd and Muzio, 2007; Clegg and Clark, 1999; Fincham, 2006), studies of the role of gender and religion in the workplace (Bolton, 2005; Essers and Benschop, 2009), and work on strategy as practice (Jarzabkowski, 2004; Johnson et al., 2007).

The work outlined above is, whilst broad, meant to capture the interest of a group of organizational sociologists in the sociology of the workplace. Some might disagree with the classification of the work as a coherent body of scholarship. The main point I am making, though, is that this work and other work like it prioritises in the study of organizations the study of people doing management and being 
managed, the influences on, and of, their actions and the outcomes in terms of organizational forms, commercial successes and personal and collective social costs. As such it is not that far removed from economic geographers' interest in the embedded TNC and, to paraphrase Yeung (2005b), the actors, structures, power relations and outcomes associated with relational spaces. Moreover, in work badged as 'critical management studies' (see Alvesson et al., 2009; Grey and Willmott, 2005) the theoretical tools deployed, such as the work of Foucault, Goffman and Marx, mirror tools used by geographers (see for example Larner, 2007, Jones, 2007, and Massey, 2004, respectively). Significantly though, the work of organizational sociologists does differ from that of economic geographers in one important way.

With some exceptions, the work of the organizational sociologists I have highlighted above is primarily based on studies of one site in a domestic firm or the study of one site within a TNC's network of operations. This single site focus is a key strength and is something economic geographers interested in TNCs can learn from. The detailed empirical analysis of the day-to-day micro politics provided by organizational sociologists offers a way of developing a richer understanding of the social interactions, struggles, conflicts and contests that characterise the relational space that allows TNCs to operate. As a result the work of organizational sociologists when combined with the strengths of economic geographers has the potential to identify the nature and role of management practices as situated, relationally constructed through interactions and based on language games and social tussles between different actors in firms (Delbridge and Ezzamel, 2005).

A particularly useful way of exemplifying the potential complementarity of economic geographers' and a sub-set of organizational sociologists' work is by considering the way critical management studies of identity regulation understand management practice. Such approaches, which have formed part of what 
has been broadly defined as a post-structural turn in which both theory and methods are re-orientated to prioritise fine-grained social analysis of organizational practices (Watson, 2008), gives credence to the idea that the power of managers actually lies in their ability to change, through the actions of key individuals and groups, identities and the perspectives of workers. Drawing on approaches which see identity as the main influence on an individual's understanding of 'who I am' and 'how I should act' (Alvesson et al., 2008), and assuming that identity is constructed in an ongoing manner through social interaction, linguistic exchange and conflicts and contestations between different individuals and groups (Cerulo, 1997), the concept of 'identity work' captures the way individuals are continuously forming and reforming their identity. The concept of 'identity regulation' captures the way managers, through strategic actions and interactions, influence identity work processes (Alvesson and Willmott, 2002; Sveningsson and Alvesson, 2003).

Exemplifying the nature of identity regulation, Sveningsson and Alvesson $(2003,1167)$ reveal the role of discourse and language and how "a more or less integrated, prefabricated line of using language and reasoning" lies behind management attempts to change the way people work and behave. Alvesson and Willmott (2002) further reveal the role of language in (re)positioning workers' understandings of 'who I $\mathrm{am}^{\prime}$ and 'how I should act' as part of management strategies. They outline nine different linguistic strategies:

1. Defining the person directly. The characteristics desired of the 'ideal employee' are explicitly stated.

2. Defining a person by defining others. An individual or group is compared to others who represent 'ideal' employees. 
3. Providing a vocabulary of motives. A language is created to identify and help individuals make sense of who the ideal employee is and how they act.

4. Explicating morals and values. Values are espoused, often via stories and by comparison to those values deemed unacceptable, to help workers understand how the firm wants them to act.

5. Knowledge and skills. Education and training is used to instill understanding of how an individual should view themselves as an employee and how they should act.

6. Group categorization and affiliation. Dividing up the world into 'us' and our identity and 'them' and their alterity.

7. Hierarchical location. Praising individuals and groups that embody the identity of the firm's ideal employee.

8. Establishing and clarifying the rules of the game. Laying out the 'norms' of how things are done in an explicit fashion.

9. Defining the context. Stating clearly the customs and norms of the firm and the expectations about how workers align themselves with this context.

Such studies of identity regulation draw heavily on the work of Foucault $(1980 ; 1991)$ to conceptualise language and discourse as a governmental tool that shapes conduct. However, at the same time as looking at the way managers use discourse to govern, organizational sociologists have also revealed, as Beech $(2008,56)$ puts it, that discursive strategies "can proceed in ways which have either centripetal or centrifugal identity outcomes. The dialogue might lead to reinforcement of rejection of an identity construction, or to possible points in between these two extremes". It is, then, not just the tools deployed in conflicts in firms that are revealed by organizational sociologists but also how individuals 
and groups can resist change and, as a result, how attempts to invoke change can fail or, rather than necessarily leading to one group winning at the expense of another, lead to compromises and negotiated settlements. Examples of how such subversion or corruption may be achieved include the production of alternative counter discursive regimes (Elsbach and Bhattacharya, 2001), the use of cynicism or irony as a way of questioning discursive regimes (Dent, 2003; Fleming and Spicer, 2003; Kosmala and Herrbach, 2006) and the creation of what Goffman (1967) would call a 'front stage' in which cultures promoted by identity regulation are displayed to appease management and a 'back stage' in which alternative cultures are displayed as a form of resistance (Delmestri, 2006; Costas and Fleming, 2009). Consequently, studies of identity regulation emphasise the importance of detailed, often ethnographic, studies of situated management practices.

\subsection{Transdisciplinary questions and new agendas}

So what is the value in bringing the work of organizational sociologists on identity regulation into dialogue with economic geographers' work on institutions and TNCs and what are the wider lessons that can be drawn from this about the value of transdisciplinary research? The institutions economic geographers have identified as being so important in shaping the activities of TNCs, through the customs and norms they help produce, in many ways shape an individual's understanding of 'who I am and how I should act' as a worker. In TNCs, when actors at headquarters attempt to manage actors working in overseas subsidiaries, particularly when home-country best practices are rolled out in overseas subsidiaries, conflicts emerge because amongst other things of the way the identities of workers and managers in each subsidiary - i.e. their understanding of who the firm's employees are and how they should act - are produced by place-specific institutions that differ from the institutions of the homecountry of the firm. As noted above, economic geographers have not been particularly proficient at 
studying the micro-scale subtleties of the conflicts that emerge from such differences in identity. However, in highlighting the nature of the dialogue and interaction that goes on in firms as managers and workers come into conflict about identity, the work of organizational sociologists provides a starting point for considering the nature of such institutionally inspired conflicts in TNCs. Thus collaborations between economic geographers and organizational sociologists might be said to be beneficial because they could allow the development of research of transnational identity regulation and its role in TNCs which overcomes the limitations of economic geographers' work and also allow the internationalization of the work of the organizational sociologists studying identity regulation in non-global firms. But this is not the only potential end result of dialogue between the two groups and is, indeed, an outcome that could be critiqued because, inevitably, there will be individuals and sub-sets of the sub-sets of scholars I have discussed here who have already embarked on such a journey.

The development of a genuinely transdisciplinary approach means generating analytical traction that neither organizational sociologists nor economic geographers alone, or any other uni-, multi- or interdisciplinary research grouping, could achieve through the development of new questions. A transdisciplinary approach would be based on questions that focus on the dialectic relationships that mean, depending on the management tactics used - with the choice of tactics and their success being influenced by the societal embeddedness of the actors involved - different and apparently messy, hard to categorize and contingent organizational forms will emerge. In particular, this involves revealing the diversity of relations within TNCS and, rather than characterising relations within firms as universal and consistent, recognising that relations vary depending on (a) the types of negotiations, power games and compromises that play out in the firm, something related to (b) the spatial dynamics of a relationship and variations in the societal embeddedness of situated actors. Hence, a transdisciplinary understanding 
of the TNC as an embedded community means asking questions about stretched relational spaces that involve interactions between managers and workers in different countries in a way that recognizes the insights economic geographers have provided into societal and network embeddedness. But, this must be done without losing organizational sociologists' focus on questions about the detail of the power strategies employed. Such questions might lead to new insights, framed by the idea that the TNC is an embedded community, addressing issues such as:

- What are the causes of organizational politics and workplace conflicts in embedded social communities? Such questions offer the opportunity to more clearly tease out the link between forms of societal embeddedness, different forms of workplace conflict, and the management, structure and success or failure of TNCs.

- How do coalitions and fractures emerge and define organizational politics in embedded communities and what effect do these have on identity regulation (power) strategies? These types of questions will help reveal the way degrees of difference between embedded actors lead to more or less fractious relationships that require different types of negotiations between contending parties.

- What effect does the recourse to virtual versus embodied interactions in identity regulation (power) strategies have on the micro politics of interaction between contending parties and under what circumstances is one mode of interaction chosen over another? Such questions will draw attention to the very real effects on regulation strategies of spatially distributed management and workers in TNCs. In particular, as an embedded community, the sociotechnical architecture that produces the community and the way the embeddedness of actors defines the structure of this architecture and its role in conflicts and their resolution will be better revealed. 
These questions are just exemplars of a wider range of questions that emerge from the types of transdisciplinary collaborations being promoted here. Such approaches also open up a series of methodological questions. Space prevents a detailed discussion of methodology here, but, suffice to say, a diverse range of approaches, from questionnaire surveys through to ethnography and conversation analysis need to be appropriated, triangulated and when necessary re-designed to deal with such transdisciplinary questions.

To a certain extent and as already alluded to, some economic geographers and organizational sociologists have already begun to consider the type of transdisciplinary questions outlined above. There already exists, for example, an impressive body of work that explicitly studies TNCs, the affects of their embeddedness on management practices and the situated manifestations of this in the form of workplace power relations such as those associated with identity regulation (see for example Dörrenbächer and Gammelgaard, 2006, Ferner et al., 2005, 2006; Morgan, 2001a, 2001b). In particular, this work effectively couples theories of power (Clegg et al., 2006) to the extensive literature on national business systems (Whitley, 1998) and the varieties of capitalism (Hall and Soskice, 2001) to explore the compromises and adjustments in management strategies that are needed to accommodate different worker norms, values and attitudes as a result of institutional legacies. Similarly Brown et al. (2006) show how place can act as a tool for worker resistance to identity regulation when used as a way of constructing shared counter-discourses (e.g. we do it like this in Italy) based on particular societal norms, whilst Ferner et al. (2005) reveal how the power relations that underlie management in TNCs are intimately related to not just headquarters-subsidiary duals associated with differential power relations but also to conflicts caused by different and institutionalized place-specific norms about management. 
Such work exemplifies, then, how much progress can be made if dialogue between scholars emerging from very different disciplinary backgrounds is used to develop new questions for research. And this means not just confining dialogues to those between economic geographers and organizational sociologists. Dialogues between these groups and those from disciplines such as anthropology, history and law may be just as rewarding. And this points to why my bigger argument about the need for not only studies of TNCs but also critical perspectives on international business more widely to value transdisciplinary approaches to research is important: the new questions raised cut across and push forward a wide range of debates and lay the foundations for important future research.

Before ending it is, however, important to acknowledge that in bringing the work of scholars from different disciplines into dialogue some caution does have to be exercised. In the case of economic geographers and organizational sociologists issues exist, as Watson (2008) notes, in relation to the importance of not allowing collaboration to compromise the rich empirical analyses that organizational sociologists are so good at developing. Such a compromise is something economic geographers have been perhaps too quick to make, something reflected in the differences in the methodologies of economic geographers and organizational sociologists. The former tend to rely on semi-structured corporate interviews as the main tools for getting to grips with how TNCs operate. The latter also use interviews but usually alongside long term observational work that explains and is explained by the findings of interviews. The different approach of organizational sociologists allows them to develop a more nuanced understanding of how management happens in practice and of the micro-politics of such management processes, suggesting economic geographers might have to be willing to adopt alternative methodologies to maximize the value of dialogue with organizational sociologists. From another perspective there is a danger that collaborations lead to research that is, as Granovetter (1985) warned, 
'over-socialized'. Ensuring the structures of societal embeddedness highlighted by geographers, which coexist alongside network embeddedness, are not lost in discussions of micro politics is vital. After all, it is the interaction of the two that defines the relational spaces of management in TNCs. There is also the danger that detailed analyses of micro politics have little to say about the wider implications of changes negotiated as part of encounters between workers and managers, for the firm and for individuals. This means research should focus on systematic changes in the organization of the firm - or lack of them that result from interactions between managers and workers and not just the interactions themselves. This is something economic geographers prioritize in their relational approach and should not be lost in any collaboration. What I am suggesting, then, is that transdisciplinary working has the potential to leverage detailed explanations of the way TNCs operate that the approaches of single disciplinary groupings on their own cannot, as long as collaborations do not lead to the weakening of the existing strengths of each group's work.

\section{Conclusions}

In this paper I have called for critical studies of international business to be based on transdisciplinary dialogue that allows the complexities of TNCs, as embedded social communities, to be unpicked through new questions for research. Taking as my starting point the assertion that the management of TNCs is both influenced by structure - in the form of embeddedness that influences the cognitive, cultural, social and political characteristics of a firm's workers - and agency - in the form of social interactions that characterise management work in TNCs -, I have considered how the work of economic geographers and organizational sociologists might complement each other to develop a more sophisticated analysis of TNCs as embedded social communities. The example of transnational identity 
regulation was used to substantiate this argument. However, other topics relating to the management of TNCs, such as issues surrounding knowledge, learning, innovation and entrepreneurship could equally benefit from dialogues between economic geographers and organizational sociologists (see for example the case made by Yeung, 2009).

As such, the main contribution of this article is to highlight the need for critical studies of international business to avoid blinkered approaches to studying TNCs and disciplinary silos that inevitably limit the analytical traction available to researchers. Studying international business, and TNCs in particular, is an incredibly complex task and exploring what can be learned from others outside of one's own disciplinary frame and using this to reframe research questions seems essential in order to develop meaningful and sophisticated representations of the social life of management in firms. Here I have promoted a pragmatic approach to such collaborations that involves working within paradigms and with researchers with shared theoretical, epistemological and ontological frames of reference, if not a shared empirical foci of analysis. This is not to say attempting to work across paradigms and critiquing other paradigms is not productive. Rather my argument stems from reflections on an approach I have found to yield the most analytical traction and generate the most interesting research questions (and occasionally answers).

As noted, there are dangers associated with the pragmatic transdisciplinary approach I have outlined here. Theoretical incompatibilities, the need to avoid analytical dilution and ensure analytical magnification, and the need to sustain constructive critique rather than stagnant consensus have to be wrestled with and born in mind at all times. As a result, I believe there is still an important place for disciplinary debates which can act as the starting point for transdisciplinary dialogues, as long as it is 
recognised that pragmatically there seems to be much to learn from collaborative approaches that cross what are, after all, socially constructed scholarly divides.

\section{Acknowledgements}

The pragmatic collaboration described here was put into practice thanks to ESRC grant RES-000-22-2957 (see http://www.lancs.ac.uk/professions/professional ed/). The ideas about 'transnational identity regulation' outlined above were also developed as part of this project. Sarah Hall, Daniel Muzio Christoph Dörrenbächer and one further anonymous referee provided useful and much appreciated feedback on an earlier version of this paper. Of course, none of the above named should be held responsible for the ideas expressed here.

\section{References}

Ackroyd, S. (2004) 'Less bourgeois than thou', A critical review of studying management critically. Ephemera: Theory \& Politics in Organization, 4, 165-70.

Ackroyd, S. \& Muzio, D. (2007) 'The Reconstructed Professional Firm: Explaining Change in English Legal Practices', Organization Studies, 28, 729.

Ackroyd S \& Thompson P, (1999) Organizational misbehaviour (Sage, London)

Adler, P. S., Forbes, L. C. \& Willmott, H. (2007) 'Critical Management Studies', The Academy of Management Annals, 1, 119-79.

Adler, P. S., Kwon, S. W. \& Heckscher, C. (2008) 'Professional work: The emergence of collaborative community', Organization Science, 19. 
Alvesson, M., Ashcraft, K. \& Thomas, R. (2008) 'Identity matters: reflections on the construction of identity scholarship in organization studies', Organization, 15, 5-28.

Alvesson, M. \& Willmott, H. (1992) Critical management studies, Sage Publications Ltd.

Alvesson, M. \& Willmott, H. (2002) 'Identity regulation as organizational control: producing the appropriate individual', Journal of management studies, 39, 619-44.

Alvesson, M., Willmott, H. \& Bridgman, T. (2009) The Oxford Handbook of Critical Management Studies, Oxford University Press, USA.

Audretsch, DB. and M. Feldman (1996). "R\&D spillovers and the geography of innovation " American Economic Review 86: 630-640.

Beaverstock, J. V. (2004) "Managing across borders': knowledge management and expatriation in professional legal service firms', Journal of economic geography, 4, 157-79.

Beder, S. (2002) Global spin, Green Books Totnes.

Beech, N. (2008) 'On the nature of dialogic identity work', Organization, 15, 51-74.

Bolton, S. C. (2005) 'Women's Work, Dirty Work: The Gynaecology Nurse as'Other", Gender Work and Organization, 12, 169-86.

Bolton, S. C. \& Boyd, C. (2003) 'Trolley dolly or skilled emotion manager? Moving on from Hochschild's Managed Heart', Work, Employment \& Society, 17, 289.

Brown, A., Humphreys, M., Down, C. \& Campus, J. (2006) 'Organizational identity and place: a discursive exploration of hegemony and resistance', Journal of Management Studies, 43, 231-57.

Bunnell, T. \& Coe, N. (2001) 'Spaces and scales of innovation', Progress in Human Geography, 25, 56989.

Burawoy M, (1991) Manufacturing consent (University of Chicago Press, Chicago)

Burell, G. \& Morgan, G. (1979) Sociological Paradigms and Organisational Analysis Elements of the Sociology of Corporate Life London, Heinemann. 
Cerulo, K. (1997) 'Identity construction: New issues, new directions', Annual review of Sociology, 23, 385-409.

Clark, G. L. \& Wrigley, N. (1997) 'The spatial configuration of the firm and the management of sunk costs', Economic Geography, 73, 285-304.

Clegg, S., Courpasson, D. \& Phillips, N. (2006) Power and organizations: Sage Publications Ltd.

Clegg, S. \& Palmer, G. (1996) The politics of management knowledge, London: Sage Publications Ltd.

Clegg, S. \& Clarke, T. (1999) 'Intelligent organizations?', In Clegg, S., Ibarra-Colado, E. \& BuenoRodriquez, L. (eds) Global management. Universal theories and local realities. London, Sage.

Clegg, S., Courpasson, D. \& Phillips, N. (2006) Power and organizations, London: Sage.

Coe, N. \& Wrigley, N. (2006) 'Business as usual? A response to Palmer, Owens, and Sparks', Environment and Planning. A, 38, 1783-88.

Coe, N. \& Yeung, H. W.-C. (2001) 'Geographical perspectives on mapping globalisation', Journal of economic geography, 1, 367-80.

Coe, N. \& Lee, Yong-Sook. (2006) 'The strategic localization of transnational retailers: the case of Samsung-Tesco in South Korea', Economic Geography, 82, 61-88.

Costas, J. \& Fleming, P. (2009) 'Beyond dis-identification: A discursive approach to self-alienation in contemporary organizations', Human Relations, 62, 353-78.

Currah, A. \& Wrigley, N. (2004) 'Networks of organizational learning and adaptation in retail TNCXs', Global Networks, 4, 1-23.

Delbridge, R. \& Ezzamel, M. (2005) 'The Strength of Difference: Contemporary Conceptions of Control', Organization, 12, 603-18.

Delmestri, G. (2006) 'Streams of inconsistent institutional influences: middle managers as carriers of multiple identities', Human Relations, 59, 1515-41. 
Dent, M. (2003) 'Managing doctors and saving a hospital: Irony, rhetoric and actor networks', Organization, 10, 107-27.

Dicken, P. (2000) 'Places and flows: situating international invetsment', In Clark, G., Feldman, M. \& Gertler, M. (eds) The Oxford handbook of economic geography. Oxford, Oxford University Press.

Dicken, P., Kelly, P. F., Olds, K. \& Yeung, H. W.-C. (2001) 'Chains and network, territories and scales: towards a relational framework for analysing the global economy', Global Networks, 1, 89-112.

Dörrenbächer, C. \& Gammelgaard, J. (2006) 'Subsidiary role development: The effect of micro-political headquarters-subsidiary negotiations on the product, market and value-added scope of foreignowned subsidiaries', Journal of International Management, 12, 266-83.

Edquist, C. (1997). Systems of innovation - their emergence and characteristics Systems of innovation. In Edquist C (Ed) Systems of Innovation. Technologies, institutions and organizations. London, Pinter: 1-35.

Elsbach, K. \& Bhattacharya, C. (2001) 'Defining who you are by what you're not: Organizational disidentification and the National Rifle Association', Organization Science, 393-413.

Essers, C. \& Benschop, Y. (2009) 'Muslim businesswomen doing boundary work: The negotiation of Islam, gender and ethnicity within entrepreneurial contexts', Human Relations, 62, 403.

Ezzamel, M. \& Willmott, H. (1998) 'Accounting for teamwork: a critical study of group-based systems of organizational control', Administrative Science Quarterly, 43.

Faulconbridge, J. R. (2008a) 'Managing the transnational law firm: a relational analysis of professional systems, embedded actors and time-space sensitive governance', Economic Geography, 84, 185210.

Faulconbridge, J. R. (2008b) 'Negotiating cultures of work in transnational law firms', Journal of Economic Geography, 8, 497-517. 
Faulconbridge, J. R. \& Muzio, D. (2007) 'Reinserting the professional into the study of professional service firms: the case of law', Global Networks, 7, 249-70.

Faulconbridge, J. R. \& Muzio, D. (2008) 'Organizational professionalism in globalizing law firms', Work, Employment and Society, 22, 7-25.

Faulconbridge, J. R. \& Muzio, D. (2009) 'The financialization of large law firms: situated discourses and practices of reorganization', Journal of Economic Geography, 9, 641-61.

Ferner, A., Almond, P. \& Colling, T. (2005) 'Institutional Theory and the Cross-National Transfer of Employment Policy: The Case of'Workforce Diversity'in US Multinationals', Journal of International Business Studies, 36, 304-22.

Ferner, A., Quintanilla, J. \& Sanchez-Runde, C. (2006) 'Introduction: multinationals and the multilevel politics of cross-national diffusion', In Ferner, A., Quintanilla, J. \& Sanchez-Runde, C. (eds) Multinationals, institutions and the construction of transnational practices. Convergence and diversity in the global economy. Basingstoke, Palgrave Macmillan.

Fincham, R. (2006) 'Knowledge work as occupational strategy: comparing IT and management consulting', New Technology, Work and Employment, 21, 16-28.

Fleming, P. \& Spicer, A. (2003) 'Working at a cynical distance: Implications for power, subjectivity and resistance', Organization, 10, 157-79.

Foucault, M. (1980) 'Power/Knowledge, trans. Colin Gordon, New York', Pantheon.(1991)'Governmentality', in G. Burchell, C. Gordon and P. Miller (eds) The Foucault Effect: Studies in Governmentality, Chicago: University of Chicago Press.

Foucault, M. (1991) "Governmentality' (translated by Braidotti, R and revised by Gordon, C) ', In Burchell, G., Gordon, C. \& Miller, P. (eds) The Foucault Effect: Studies in Governmentality. Chicago, IL, University of Chicago Press. 
Froud, J., Johal, S., Leaver, A. \& Williams, K. (2006) Financialization and strategy. Narrative and numbers, London and New York, Routledge.

Gertler, M. (2004) Manufacturing culture., Oxford, Oxford University press.

Goffman, E. (1967). Interaction ritual: essays on face to face behaviour. New York, Doubleday and Company.

Granovetter, M. (1985) 'Economic action and social structure: the problem of embeddedness', The American journal of sociology, 91, 481-510.

Grey, C. \& Willmott, H. (2005) Critical management studies: A reader, Oxford University Press, USA.

Hall, P. A. \& Soskice, D. (2001) Varieties of capitalism. The institutional foundations of comparative advantage, Oxford, Oxford University Press.

Hall, S. and L. Appleyard (2009). "City of London City of learning? Placing business education within the geographies of finance." Journal of Economic Geography 9(5): 597.

Hardy, C. (1996) 'Understanding power: bringing about strategic change', British Journal of Management, 7: S3-S16.

Hess, M. (2004) 'Spatial relationships? Towards a reconceptualization of embeddedness', Progress in Human Geography, 28, 165-86.

Hodgson, G. (2006) 'What are institutions', Journal of Economic Issues, 40, 875-94.

Jarzabkowski, P. (2004) 'Strategy as practice: Recursiveness, adaptation, and practices-in-use', Organization Studies, 25, 529.

Johnson, G., Langley, A., Melin, L. \& Whittington, R. (2007) Strategy as practice: research directions and resources, Cambridge Univ Pr.

Jones, A. (2005) 'Truly global corporations? Theorizing organizational globalisation in advanced businessservices', Journal of economic geography, 5, 177-200. 
Jones, A. (2007) 'More than 'managing across borders?'The complex role of face-to-face interaction in globalizing law firms ', Journal of Economic Geography, 7, 223-46.

Kosmala, K. \& Herrbach, O. (2006) 'The ambivalence of professional identity: On cynicism and jouissance in audit firms', Human Relations, 59, 1393-428.

Larner, W. (2007) 'Expatriate experts and globalising governmentalities: the New Zealand diaspora strategy', Transactions of the Institute of British Geographers NS, 32, 331-45.

Lundvall, B. and B. Johnson (1994). "The Learning Economy." Industry and Innovation 1(2): 23-42.

Massey, D. (2004). Uneven development: social change and spatial divisions of labour. Reading economic geography. T. J. Barnes, J. Peck, E. Sheppard and A. Tickell (Eds). Oxford, Blackwell: 111124.

Morgan, G. (2001a) 'The multinational firm: organizing across institutional and national divides', In Morgan, G., Kristensen, P. H. \& Whitley, R. (eds) The multinational firm. Oxford, Oxford University Press.

Morgan, G. (2001b) 'Transnational communities and business systems', Global Networks, 1, 113-30.

Murphy, J. T. (2006). "Building trust in economic space." Progress in Human Geography 30(4): 427-450.

North, D. C. (1990) Institutions, institutional change and economic performance, Cambridge, Cambridge University Press.

Orlikowski, W. (2002) 'Knowing in practice: enacting a collective capability in distributed organizing', Organization Science, 13, 249-73.

Palmer, M., Owens, M. \& Sparks, L. (2006) 'Transdisciplinary (retail) research: the business of geography and the geography of business', Environment and Planning A, 38, 1775.

Peck, J. (2005) 'Economic sociologies in space', Economic Geography, 81, 129-74.

Peck, J. \& Yeung, H. W.-C. (eds) (2003) Remaking the global economy, London, Sage.

Polanyi, K. (1944) The Great Transfromation., New York, Rinehart. 
Roberts, J. (2006) 'Limits to communities of practice', Journal of Management Studies, 43, 623-39.

Sunley, P. (2009) 'Relational economic geography: a partial understanding or a new paradigm?' Economic Geography, 84: 1-26.

Sveningsson, S. \& Alvesson, M. (2003) 'Managing managerial identities: Organizational fragmentation, discourse and identity struggle', Human Relations, 56, 1163.

Swan, J. \& Scarborough, H. (2005) 'The politics of networked innovation', Human relations, 58, 913-43.

Thompson P, 2003, "Disconnected capitalism: or why employers can't keep their side of the bargain" Work, Employment \& Society 17 359-378

Veblen, T. (1919) The Place of Science in Modem Civilisation, New York, BW Heubsch

Watson, T. (2008) 'Managing identity: Identity work, personal predicaments and structural circumstances', Organization, 15, 121-43.

Weingart, P. \& Stehr, N. (eds) (2000) Practising Transdisciplinarity Toronto, University of Toronto Press. Whitley, R. (1998) 'Internationalization and varieties of capitalism: the limited effects of cross-national coordination of economic activities on the nature of business systems', Review of international political economy, 5, 445-81.

Wickson, F., Carew, A. L. \& Russell, A. W. (2006) 'Transdisciplinary research: characteristics, quandaries and quality', Futures, 38: 1046-59.

Wrigley, N., Coe, N. \& Currah, A. (2005) 'Globalizing retail: conceptualizing the distribtuion-based transnational corporation (TNC)', Progress in Human Geography, 29, 437-57.

Yeung, H. W.-C. (2005a) 'Organizational space: a new frontier in international business strategy?', Critical Perspectives on International Business 1, 219-40.

Yeung, H. W.-C. (2005b) 'Rethinking relational economic geography', Transactions of the Instittue of British Geographers NS, 30, 37-51. 
Yeung, H. W.-C. (2009) 'Transnationalizing entrepreneurship: a critical agenda for economic geography', Progress in Human Geography, 33, 210-35.

\section{About the author}

James Faulconbridge is an Economic Geographer by training. His research examines the globalization of knowledge-intensive and professional service firms, such as advertising, architecture and law firms, the way communities of practice emerge and generate spaces of learning in these firms, and the management practices used to deal with the effects of institutional embeddedness on global knowledge-intensive and professional service firms worldwide offices. Previous research has been published in journals such as Environment \& Planning A, The Journal of Economic Geography and Work and Occupations. A forthcoming book, to be published by Routledge, explores the globalization of advertising agencies.

Email: j.faulconbridge@lancaster.ac.uk 